\title{
Internalisation of Relations
}

\section{Paweł Rojek ${ }^{1}$ (i)}

Received: 22 July 2019 /Revised: 19 December 2019 / Accepted: 3 January 2020/

Published online: 29 January 2020

(C) The Author(s) 2020

\begin{abstract}
The discussion about internal and external relations usually concerns what kind of relations exist. In this paper, I take up another question, namely whether external relations can become internal and internal relations become external. My starting point is the concept of a "relational collapse" formulated by the Soviet and Ukrainian philosopher Avenir Uemov. I try to develop his idea, distinguishing two senses of internal relation, based on the concepts of ground and essence. As I argue, internalisation may consist either on groundation or essentialisation of relations. Contrary to Uemov, both of these processes seem to be reversible, so we should also introduce the concepts of ungroundation and accidentalisation of relations. These four concepts form a framework for the general theory of internalisation and externalisation of relations. This framework seems to be particularly useful in analysis of some problems in social ontology.
\end{abstract}

Keywords Relational collapse · Avenir Uemov · Internal relations · External relations · Internalisation · Externalisation · Groundation · Essentialisation · Social ontology

\section{Introduction}

At the turn of the twentieth century, there was a famous dispute in British philosophy around internal and external relations. Internal relations were usually understood as essential and resulting from the properties of the terms of relations, and external relations as accidental and not grounded in in the properties of the relata. Some philosophers thought that all relations are internal, some considered that they are all external, and some believed that all relations are partly internal and partly external (Ewing 1934; Candlish 2007). Today, most authors, quite conciliatory, accept that relations can simply be of different types. Some, such as the similarity between

Paweł Rojek

pawel.rojek@uj.edu.pl

1 Institute of Philosophy, Jagiellonian University, ul. Grodzka 52, 33-332 Kraków, Poland 
properties, are internal, whereas others, such as spatial relations between things, are external. The former are now usually considered to be reducible to the properties of terms of relations, and the latter not (Marmodoro and Yates 2016; Hakkarainen et al. 2018).

This whole dispute, more than a century old, concerned the question of what kind of relations exist, not the question whether relations can change their status. It has been discussed whether there are internal and external relations, and not whether external relations can become internal, and vice versa. In this paper, I would like to deal with this rarely noticed possible dynamic aspect of the problem of external and internal relations.

The supposed transition from external into internal relation can be called internalisation, and the transformation of internal relation into external may be described as externalisation of relations. It seems that these two concepts could be very useful in describing and analysing many phenomena, especially those studied in biology, psychology and the social sciences. One of the basic concepts of these disciplines is development, which can be prima facie interpreted exactly as externalisation or internalisation of relations. On the one hand, it seems that in many cases something that was essential for a thing at an early stage of development becomes accidental at a later stage. For instance, an adult no longer needs to be taken care of by his or her parents. This looks like externalisation of some relations. On the other hand, something that was accidental at the beginning of the process might apparently become essential at later stages. For example, a child in the process of socialisation could accept different views of the world, but since one of them is adopted, it becomes constitutive for its personal identity. This might be viewed as a case of interalisation of some relations. Perhaps, then, it is not a coincidence that the process of adopting norms in sociology is called precisely internalisation.

As far I know, the only author to address directly the problem of the transformation of relations was the Soviet and Ukrainian philosopher Avenir Uemov (1928-2012), a logician, ontologist and systems' theoretician, the founder of the original systemic research school in Odessa (see Tsofnas and Góralski 2014). In the mid-seventies, he dealt with the issue of internal relations on the margins of his works on a general theory of systems. In his English article Problem of Direction of Time and the Laws of Systems' Development (Uemov 1975), which was then almost entirely incorporated into his Russian book Sistemnyi podkhod i obshchaia teoriia sistem [System Approach and the General System Theory] (Uemov 1978, pp. 225-231), Uemov pointed out that in some cases relations can affect their terms in such a way that relations that are external to them after some time become internal. He called this situation a "relational collapse", alluding to the concept of gravitational collapse known from physics.

In the case of the latter an arbitrary material entity, including photons, cannot leave a certain sphere (zone) once it has entered this sphere. The relational collapse means that once things enter a certain relation they reach such a state (resulting from the effect of this relation) that they cannot get rid of this relation otherwise than by abolishing their existence as given things (Uemov 1975, p. 99; 1978, pp. 228-229). 
In relational collapse, the relation which was previously merely external, i.e., accidental for its terms and not resulting from their existence, becomes a relation that is essential and grounded in relata, hence an internal one. What is important, Uemov believed that the process of turning external relations into internal ones is irreversible and can thus serve as a criterion for the direction of the flow of time. Subsequently, Uemov's idea was picked up by some his students and used, inter alia, to explain the nature of the internalisation of social norms.

In this paper, I attempt to reconstruct, revise and develop the concept of Uemov's relational collapse. It seems to me that he captured an important aspect of reality. I believe he was generally right that things can really change under the influence of their relations. It seems to me, however, that Uemov did not notice that the concept of internal relations has two close but separate meanings. It was sometimes assumed that internal relations both result from the natures (i.e. sums of non-relational properties) of its terms and are also essential for the terms; nevertheless, as it is now commonly acknowledged, there are relations that result from the natures of the terms but are not essential to the terms (Johansson 1989, p. 119-120; Campbell 1990, p. 110-113; Simons 2016, p. 114-115; Marmodoro and Yates 2016: 7-14). This ambiguity of the concept of "internal relation" leads to distinguishing two separate meanings of "internalisation": groundation, that is a change of relation into a relation grounded in the natures of terms, and essentialisation, that is the transformation of a relation into a relation essential to the terms. Groundation means that the terms of relation gain properties, which ground the existence of the relation, and essentialisation means that the existence of relata become dependent on the relation. Moreover, it seems that the argument formulated by Uemov for the irreversibility of the relational collapse is based on the confusion of these two senses of the internality of relations. Therefore, instead of the irreversible transitions of external relations into internal, one should rather speak of two distinct processes of internalisation and externalisation of relations, and more precisely of even four varieties: groundation and ungroundation as well as essentialisation and accidentalisation of relations. All these distinctions form an expanded conceptual framework, which, as it seems, may help in the analysis of various phenomena, especially the concept of development in biology, psychology, and the social sciences.

First, in Section 2, I introduce the basic concepts of Uemov's general theory of systems, his distinction between internal and external systems, and his idea of relational collapse. In Section 3 I discuss a few available applications of the concept of relational collapse, focusing on the analysis of internalisation of norms in sociology, suggested by Uemov's student, Arnold Tsofnas. Next, in Section 4, I argue that the hidden ambiguity of the crucial concept of internal relations leads to the ambiguity of the whole of Uemov's idea of relational collapse and all its possible applications. As I try to show in Section 5, it also undermines his argument for the irreversibility of the relational collapse. As a result, my criticism of Uemov's idea leads to the formulation of a general theory of internalisation and externalisation of relations, which I sketch in Section 6. 


\section{The Concept of Relational Collapse}

Avenir Uemov mainly dealt with the general theory of systems. This theory, anticipated by Aleksandr Bogdanov (1906), and afterwards famously formulated by Ludwig von Bertalanffy (1968), was intensively developed in the Soviet Union. After Stalinism, general theory of systems enjoyed high support from the authorities, who not only considered it as a way of modern developing of some categories of Marxism-Leninism, but also hoped that it could improve the failing Soviet planned economy. Yet, a large part of Uemov's work can be definitely counted as investigations in formal ontology. One may even suspect that he practised metaphysics under the cover of systems' theory. Indeed, his famous book Veshchi, svoistva i otnosheniia [Things, Properties, and Relations] (Uemov 1963), in which he argued for the irreducibility of the categories of things, properties and relations, is clearly an ontological treatise. His already mentioned fundamental work on systems' theory, Sistemnyi podkhod i obshchaia teoriia sistem [System Approach and the General System Theory] (Uemov 1978), also includes many interesting ontological topics. After the fall of the Soviet Union, Uemov started to deal with metaphysics even more directly. The results were original logicalphilosophical comments of Aristotle's works and interesting reflections on the philosophy of God (Uemov 2010). I am not, however, going to deal here with the broad context of Uemov's theory, neither in general theory of systems, nor in Soviet Marxism-Leninism. I rather focus on some of his particular ideas which can be, I believe, presented and discussed separately.

Uemov defined a system as a set of things related by a certain relation that has a specific property. It is thus a complex structure involving three different ontological categories connected with each other. A general definition of a system is as follows:

$$
\text { (D1) }(m) S=\mathrm{df}_{\mathrm{d}}[R(m)] P \text {. }
$$

A certain number of things $m$ (variable $m$ may stand for multiplicity of things) is a system, i.e. it has the property $S$, if and only if it is related by a relation $R$, which in turn has a special property $P$ (Uemov placed the symbol of property on the right side of the symbol of object, whereas the symbol of a relation on the left) (this rough definition is taken from Uemov 1975, p. 96, for more detailed one see Uemov 1978, p. 165; 1999, p. $365 ; 2010$, p. 121-122). The multiplicity of things, which form a basis of the system, Uemov called substrate; the relation obtaining between these things he called structure; finally, the characteristic property of this relation he called, somewhat misleadingly, the concept of the system (in Russian: substrat, struktura, and poniatie; whenever possible, I adopt English terms accepted by Uemov himself in the translations of his works). This specific property of the system-making relation varies depending on the type of system.

One of the most important achievements of Uemov was a construction of a special logical calculus dedicated specifically for system studies, called the Language of Ternary Description (LTD) (Uemov 1999, 2002, 2003; Leonenko 2000/2001). This rather complicated nonclassical logic is founded on three basic categories, involved in the definition of system, namely things, properties and relations. Moreover, there are three kinds of variables in LTD: definite, denoted by $t$, indefinite, denoted by $A$, and arbitrary, denoted by $a$. Variables can be 
indexed, as in Russell's theory of descriptions, with inverted Greek letter ı (iota), repeated or subscripted if necessary. In this paper, however, I will not use this powerful, yet quite complicated and definitely unfamiliar language. I will instead present simplified formulas, such as (D1), also sometimes used by Uemov for introductory purposes.

The general definition of system as a multiplicity of things connected by relation bearing a specific property allows to outline some fundamental issues of the theory developed by Uemov. Systems can be described in terms of the relationships between their substrata (things), structures (relations between things) and concepts (properties of relations). For example, in some systems, the number of things that make up their substrata may change, while in others it must remain constant. Further, in systems of one kind their concepts allow for some variability of structures, while in others they define them unambiguously. Finally, it is also possible to examine the relationship of the substrate, that is, of the things building the system, to the structure, i.e. to the relation which makes up the system from the things. The distinction between internal and external systems belongs precisely to the latter type of system parameters.

Uemov pointed out that the relations that make up the system structure may be either internal or external for the elements of system substrate. As he explained,

The internal relation between objects $x_{1}, \ldots, x_{\mathrm{n}}$ is viewed as a relation which is indispensable for the existence of these objects. The external relation is then determined not only by the related objects themselves but also by certain conditions depending on external objects (Uemov 1975, p. 98).

An example of an internal relation, given by Uemov, is the older than obtaining between Peter and John, and an example of external relation is the relation of holding a higher position at work (Uemov 1975, p. 98). From the very existence of Peter and John it follows that one of them is older than the other, but it does not follow that one of them is the superior to the other. In the case of internal relations, the very existence of the relata implies their connection by the relation, which can be presented in the following way:

$$
\text { (D2) } m \rightarrow R(m) \text {. }
$$

If things $m$ exist (again, $m$ may stand for many things), then there also exists an internal relation binding them $R$; implication is apparently considered here as a strict implication (this definition is taken from Uemov 1968, p. 109, for more developed definitions in LTD adopting different kinds of implication see Uemov 1978, p. 165; 2002, p. 150).

Uemov used the concept of internal relation in many contexts. In particular, he pointed out that this concept is useful for the explanation of the concept of the law of nature, which he analysed as an internal relation between the properties (Uemov 1963, p. 135, Uemov 1968 , p. 108-109). Notably, this analysis seems to be somehow precursory to the dispositionalist view of laws of nature (Shoemaker 1980; Swoyer 1982; Heil 2016). Uemov used the concept of internal relation also for the classification of systems. In internal systems, the structure is internal to the substrate, whereas in the case of external systems, it is external. The internal system can therefore be defined as follows: 
(D3) $(m) S_{\text {int }}=$ df $\{[R(m)] P\} \wedge\{m \rightarrow R(m)\}$.

A certain multitude of things $(m)$ is an internal system, i.e. it has property $S_{\text {int }}$ if and only if the relation $R$ which create the system has a certain property $P$ and $R$ results from the very existence of its substrate $m$, i.e., in Uemov words, "if there exists [...] substrate [...], then there also exists the same systems formative relation which is materialized in this substrate" (Uemov 1975, p. 100; for the definitions in LTD see Uemov 1978, p. 165; 2002, p. 150). Examples of internal and external systems correspond to examples of internal and external relations. An example of internal system might be a set of people ordered by the relation of being older, while an example of an external system might be the same set of people ordered by professional hierarchy (Uemov 1975, p. 100). Arithmetic is also an example of an internal system, since it describes relations resulting from the nature of numbers, as well as a classical propositional calculus, which in turn deals with logical relations between sentences (Uemov 1978, p. 165).

Now, relational collapse consists in the transformation of an external system, based on external relations, into an internal system, based on internal relations. Such a change is possible because, as Uemov notes, "things existing in given relations can change as the result of the functioning of the given relations" (Uemov 1975, p. 99; 1978, p. 227). Uemov provides a number of examples illustrating this phenomenon.

If some relationship is established between people, e.g., the relation of management, then this relation will transform people regardless of whether the relation itself remains unchanged. This very property of relations was taken into account at the concluding of marriages according to the principle "if they live together - they love one another". Not only people but also inanimate things get used to one another, more precisely, they become used to mutual relations. A rubber ball which gets deformed by being bashed against a wall, rebounds and recovers its form. However, if we press a rubber ball against a wall and keep it in that position for several years, the rubber ball will become adapted to its new position. The relation has not been transformed but the rubber ball has (Uemov 1975, p. 99; 1978, p. 227-228).

The last example, with a ball and a wall, might seem unclear, since Uemov does not indicate any relation there; in a following passage, however, he clarifies that the relation involved here is having similar surface; such relation was supposed to be first external and subsequently internal for its terms. It does not suffice yet, because such relation from the very beginning might be seen as grounded on monadic spatial properties of the wall and the pressed ball. I would not, however, dismiss this example. Uemov should simply add that the very shape of the ball was on its turn grounded on purely external relation of pressing, and therefore the whole relation having similar surface could be-at the beginning of the process - considered as not grounded. Anyway, it is clear, according to Uemov, that in some cases, such as actors involved in power relation, persons living 
together or rubber balls pressed to the walls, relations may change its terms in such a way that the relation which was previously external in consequence become internal.

Now, the crucial point is that, for Uemov, in such cases the relations remain the same, but due to the modification of their terms, they are changing their status from external to internal. That is, two objects $x$ and $y$ first stay in external relation $R$ and, subsequently, $x$ and $y$ change in such way that the very same $R$ becomes internal for $x$ and $y$. This is important assumption, since all these examples might be also described as merely changes of relations, not only terms. In such interpretation, external relation $R$ between $x$ and $y$ would be simply distinct from the subsequent internal relation $R$ ' between them. There would be no transformation, but rather replacement of relation. Such reading, however, as Uemov suggests, would miss the real meaning of the process, which involves not the relations themselves, but rather their status for their terms.

I think that Uemov might be right at this point. It looks quite plausible that in all the discussed cases the relations remain the same whereas only the relata change. It seems that it is the same relation of power, for instance, which was external for actors and then becomes internal for them. Similarly, the same relation of living together was first external, and then internal for a couple. Finally, the same external relation of having similar surfaces holding between a ball and a wall transforms into an internal one. In other words, in such cases the relata get used to the relation in which they stand and in result the status of relation has changed. Therefore, I assume here the model of transformation, not of replacement of relations. Nevertheless, the alternative reading seems to be possible too.

According to Uemov, then, all these examples were supposed to show that in some cases relation which was external for its relata might become internal for them. Moreover, Uemov believed that this transformation is fundamentally irreversible.

The rubber ball which has lost its flexibility as a result of lying on the table for many years will be an example of a thing in the state of a relational collapse insofar as the relation of the resemblance of the surfaces is concerned. The ageing of the organism is evidently linked with the relational collapse into which the elements of this system enter (Uemov 1975, p. 99-100, revised translation; 1978, p. 229).

Of course, this does not mean that internal systems are eternal, but merely that the only way out of the collapse is to destroy the system's substrate. To repeat, "once things enter a certain relation they reach such a state (resulting from the effect of this relation) that they cannot get rid of this relation otherwise than by abolishing their existence as given things" (Uemov 1975, p. 99; Uemov 1978, p. 228-229).

Uemov thought that the irreversibility of relational collapse allows a solution to one of the fundamental problems in the philosophy of science, namely the problem of the criterion of flow of time. In his opinion, competitive theories, referring for instance to the asymmetry of causal relations or laws of thermodynamics, do not suffice to the adequate formulation of such a criterion. The cause does not have to precede the effect in time, and the increase in entropy in one place may be related to its decrease in another (Uemov 1975, p. 93-95). Also, other system parameters, such as diversity and 
homogeneity or simplicity and complexity, are not good criteria for the flow of time, because we are not able to determine the direction of the general evolution of the world (Uemov 1978, p. 225-226). To Uemov, the only irreversible process in the world is the relational collapse. As he concluded, "time flows in that direction which corresponds to the transition of external systems to internal systems" (Uemov 1975, p. 101; 1978, p. 230). That is, the internalisation of relations is, for Uemov, the only criterion of flow of time.

\section{Applications}

As far I know, Avenir Uemov did not develop further his original idea of relational collapse, neither was this concept widely discussed by his students. However, in the works of Uemov's school, one can find some attempts to apply the idea of relational collapse. Now I would briefly review some of them and then focus on the most inspiring one, concerning the idea of internalisation of norms in sociology.

Liudmila Terent'eva, one of the first assistants of Uemov and his longtime collaborator, pointed to the possibility of applying the concept of relational collapse in the philosophy of science. In her opinion, this concept in general applies primarily to linguistic entities, such as theories. According to her, the development of a scientific theory can be analysed as a transition from the multiplicity of theorems and observations connected by external relations to the integrated system in which all these elements are internally related. This is an example — as Terent'eva said — of "an epistemological collapse" (Terent'eva 2007, p. 14). This concept was supposed to cover Werner Heisenberg's idea of "closed theory" (Heisenberg 1974), and to constitute a criterion that distinguishes science from what Gerald Holton called "anti-science" (Holton 1993). In a later work, Terent'eva also tried to apply the idea of relational collapse to explain the relations between deduction and induction (Terent'eva 2011).

The concept of relational collapse has also found applications in psychology. Irina Ershova-Babenko, one of Uemov's students, argued that the human psyche is a complex system consisting of various mental phenomena connected by a network of different relations. These relations may be external or internal, and there can also occur a "mental relational collapse".

There is a well known operation of attention switch, used when attention, entering into a specific relation with some internal or external object, goes into a "loop". In this case, the only way to get out of this state is to rapidly switch attention to something else, making the earlier object disappear (ErshovaBabenko 1992, p. 101).

Similar phenomena of the relational collapse, as Ershova-Babenko claimed, can also be observed on other levels of the mental system, such as the level of emotions, thought or memory. 
Finally, Arnold Tsofnas, a longtime close associate of Uemov, in the book Teoriia sistem i teoriia poznaniia [Theory of Systems and Theory of Knowledge] (Tsofnas 1999) proposed the use of the concept of a relational collapse in sociology. As he pointed out, the internalisation of social norms in the process of socialisation can be interpreted as the internalisation of relation. This is, I think, the most clear and inspiring application of Uemov's idea, hence I will present it in detail. ${ }^{1}$

First, Tsofnas pointed out that the distinction between internal and external systems, derived from Uemov's general theory of systems, allows for an account for the difference between natural and normative laws analysed by Karl Popper (Popper 1945, p. 49-50). Popper indicated that natural laws have a natural origin, describe facts, and neither change nor allow exceptions, while normative laws are established by people, do not describe facts, might be changed and, regrettably, might be, and actually are, violated. These differences result from the fact that laws of nature describe regularities of nature discovered in the world, while normative laws merely express norms, i.e. proscriptions and prescriptions formulated by some people towards others. The confusion of these kinds of laws, according to Popper, was to be one of the characteristic features of "primitive tribal or closed society" (Popper 1945, p. 49). Tsofnas proposed, developing above mentioned Uemov's view on laws of nature, that laws in general should be treated as relations, and that laws of nature should be understood as internal relations, while normative laws as external relations (Tsofnas 1999, p. 96-97). As he pointed out, the laws of nature are general, that is, they relate all objects with certain properties, and are necessary in the sense that they result from the very nature of its terms. The very nature of the elements of the world makes them enter into relations described by the laws of nature. Tsofnas even aptly proposed to call internal relations "natural" (Tsofnas 1999, p. 93-94). It is different with normative laws. Although, like laws of nature, they are general in some way, because they apply to all of their addressees, in contrast to the laws of nature, they are not necessary because they do not result from the nature of what they bind. Norms are simply "not internal, but external relations" (Tsofnas 1999, p. 96).

Now, the concept of relational collapse allows further development of the concept of normative laws outlined by Popper. As Tsofnas points out, although norms are external relations, they can become internal relations. Tsofnas wrote:

Systems of norms do not tell how the object of their regulation really works, but what it should be like ideally. Moreover, norms are directed not at self-preserva-

\footnotetext{
${ }^{1}$ The concept of the relational collapse was also adapted by the Greek historian of ancient philosophy Theocharis Kessidis (2002) and the Brazilian semioticist Jorge de Albuquerque Vieira (2006). Notably, Tsofnas also suggested using the idea of a relational collapse to justify the possibility of post-communist societies entering the path of development of democracy and the free market (Tsofnas 2006). A distant echo of Uemov's interest in the problem of internal relations is the logic of "traces of relations" proposed by his students (Shtakser and Leonenko 2011), but they do not mention the idea of relational collapse. Uemov's theory of relation was also developed by Nikolai Savusin (2016), but again, with no analysis of relational collapse.
} 
tion, like for example organisms, but the contrary, at self-liquidation. Every norm "wants to" cease to be a norm and become a law, that is, a relation which is determined by the very nature of man (Tsofnas 1999, p. 96).

And he added:

This task, in general, can be performed, thanks to "relational collapse", the presumed law of systems theory, according to which the external relations of interacting systems tend to become internal relations for them (Tsofnas 1999, p. 96-97).

In this way, norms that were external at first would have such an impact on people that they would become internal relations over time. Thus, normative laws would gradually become more like laws of nature, and the process of acquiring norms would be literally their naturalisation. In his later lectures on philosophy, Tsofnas presented the following examples:

If in childhood you were told endlessly to wash your hands before eating, then over time it becomes a habit, and then you simply cannot sit at the table with dirty hands. Was this not why biblical Moses led his people for 40 years through the desert, but to make the new laws imposed by him (from outside!) a habit and an inner need? Moral norms are more or less obeyed, and most people, within a given culture, even consider them to be "natural" (Tsofnas 2009, p. 124).

It is worth noting that, in this way, the contrast between the laws of nature and normative laws stressed by Popper becomes somehow blurred. In the internalisation process indeed, norms become grounded in human nature. In this way normative laws really transform towards natural laws. Popper wrote that "if any normative law is observed, it is the result of human control [...] and above all - the result of the introduction of sanctions, that is, punishment of those who break this law" (Popper 1945, p. 44). In spite of this, it turns out that the norms can also be respected because of a real change caused in people, which consists in producing a permanent disposition in them for some kind of actions. Aristotelian hexis or Bourdieu's habitus can therefore be regarded as the result of a relational collapse.

\section{Ambiguity of the Concept of Relational Collapse}

Now, I would like to look more closely at the concept of relational collapse. The collapse consists in the transition of a system based on external relations into a system based on internal relations. The key to this concept is therefore the distinction between external and internal relations. It seems to me that the concept of internal relations in Uemov's writings is fundamentally ambiguous. This ambiguity, as I think, requires the revision of some of Uemov's claims, in particular, his argument on the irreversibility of relational collapse. At the same time, however, the disclosure of that ambiguity allows for an interesting development of this concept. 
Uemov defined internal relations, in accordance with (D2), as following from the nature of its terms, but at the same time he suggested that they are necessary for their existence. Already in his 1963 book Veshchi, svoistva i otnosheniia [Things, properties, and relations], Uemov had defined internal relations as "based" on the properties of its terms, but only on those one, which are "essential" to them (Uemov 1963, p. 117). Next, in his 1968 text on the laws of nature, he wrote that, in the case of internal relations, "the existence of terms [...] is a condition for the existence of a relation between them" and, at the same time, that such relation "stems from [...] the essence of the connected objects" (Uemov 1968, p. 108). Finally, in a key 1975 article on relational collapse, he pointed out that internal relations, as opposed to external ones, are not only totally "determined" by their terms, but also "indispensable" for their existence (Uemov 1975, p. 98). This ambiguity is less clearly seen in the book Sistemnyi podkhod $i$ obshchaia teoriia sistem, which included this article, but simply because the section with definitions of internal relations was omitted. In an earlier chapter of this book, internal relations were defined as "determined by the related objects" (Uemov 1978, p. 8), and only once is it suggested that they are necessary for the relata (Uemov 1978, p. 72). The ambiguity of the concept of internal relations, however, returns in his later writings. For example, Uemov wrote that, in the case of an internal relation, if there are terms, "there is also a relation between them" and "it is impossible to be otherwise" (Uemov 2002, p. 149) or that internal relations are "determined by the nature of the terms", and at the same time, their terms "have them necessarily" (Uemov 2010, p. 77).

The problem is, however, that not every internal relation in the first sense of being grounded by its terms is also an internal relation in the second sense of being essential to its terms. Let's take a look at examples of relations often referred to by Uemov:

(1) Four is greater than three,

(2) Peter is John's superior.

Uemov recognised (1) as a typical example of internal relation (Uemov 1978, p. 67, see also 2002, p. 149), and (2) as a typical example of external relation (Uemov 1975, p. $98 ; 2002$, p. 149). The case (1), indeed, involves relation internal in both senses. The relation of being greater results from the natures of numbers, and it is also essential for them because it constitutes their identity. In every possible world, four is greater than three. Similarly, in the case (2) we have relation external in both senses: it does not follows from the natures of the terms and is not necessary for their existence. The mere existence of Peter and John is not a sufficient condition for their being related in this way, neither is this relation necessary for their existence. There are many possible worlds in which both Peter and John exist, even having all the same non-relational properties as in the actual world, and the relation does not obtain. But let us consider another Uemov's case:

(3) The Sun is greater than the Earth,

which he regarded as a plain example of internal relation (Uemov 1968, p. 108, see also 1978, p. 8). The relation of being greater holding between the Sun and the Earth 
is obviously internal in the first sense, that is, it follows from the natures of these two objects. In every possible world with the close duplicates of the Sun and the Earth, the sentence (3) will be true. But the relation of being greater between heavenly bodies it is not internal in the second sense, that is, it is not necessary for their existence. That the Sun is greater than the Earth is merely a contingent astronomical fact, not a necessary truth. This relation is indeed necessitated by the actual sizes of the Sun and the Earth, but these sizes are not necessary at all. There are many possible worlds with the Sun and the Earth which have different sizes. The same applies to many other examples of internal relations given by Uemov, such as "Peter is older than John" (Uemov 1975, p. 98) or "An object with a volume of four litres would occupy twice as much space as an object with a volume of two litres" (Uemov 1978 , p. 8). These relations seems to be grounded in their terms, but they are not essential for them.

The ambiguity of the concept of internal relation is obviously not just a problem for Uemov. This concept appeared in twentieth-century philosophy in discussions with British Neo-Hegelianism, and from the very beginning was understood in these two fundamental ways (see Ewing 1934; Candlish 2007; Rojek 2018, p. 19-22). First, Bertrand Russell, in his critique of Neo-Hegelians wrote that, in the case of internal relations, "there is something in the nature of two objects, on the basis of which they stand in a given relation" (Russell 1910, p. 160-161), so these relations are founded or grounded on the properties of the terms. Second, George Edward Moore in his famous debate with Neo-Hegelian theses, assumed that in the case of internal relations "any term that did not have $P$ would necessarily be different from $a$ " (Moore 1922, p. 284), so that these relations are necessary for their terms. Now, internal relations in Russell's sense, i.e. grounded in the nature or properties of terms, can be called R-internal, and internal relations in Moore's sense, i.e. essential for the terms, M-internal. It thus seems that the ambiguity of the concept of internal relations is ultimately rooted in the fundamental distinction between grounds and essences (for this distinction, see Fine 2015).

For a long time, no special attention was paid to the difference between these two meanings of internal relations. These concepts were clearly distinguished as late as at the end of the twentieth century independently by Ingvar Johansson (1989, p. 119-120) and Keith Campbell (1990, p. 110-113). Johansson called R-relations "grounded", whereas Campbell labelled them "founded". The distinction between grounded and essential relations is now widely accepted in analytic philosophy (Maurin 2002; Meinertsen 2011; Marmodoro and Yates 2016; Simons 2016; Hakkarainen et al. 2018). These two meanings of internal relations gives a simple classification of relations (see Table 1).

Table 1 Classification of relations

\begin{tabular}{|c|c|c|}
\hline & M-internal & M-external \\
\hline R-internal & Four is greater than three & The Sun is greater than the Earth \\
\hline R-external & & Peter is John's superior \\
\hline
\end{tabular}


The first category includes relations grounded and necessary for their terms. These are internal relations in both indicated senses. An example of such a relation is, for Uemov, greater than, holding between numbers. The second category is formed by relations external in both senses, i.e. not entailed by the terms and not essential to their identity. An example of such a relation is being a superior. The third example by Uemov, greater than, holding between concrete things, such as the Sun and the Earth, belongs to the third category of relations that are grounded, but not essential. This example shows that being grounded in relata is not the same as being essential to them. Is there a fourth type of relations that would be M-internal but R-external, that is, which would be essential but not grounded? At first glance, they seem impossible, but perhaps the relation of being created between God and the world could be placed here. It seems that according to Aquinas, created things cannot exist without that relation, but it does not follow from their natures (Ward 2010; cf. García Encinas 2013). However, I will not deal with this issue here.

It seems that nowadays the Russellian sense of internal relation is much more popular than Moorean. Contemporary debates in ontology of relation usually concern $\mathrm{R}$-external and R-internal relations. In particular, R-external relations are now considered as the only candidates for being true relations, because R-internal relations are usually thought to be subjects of ontological reduction. If they are necessitated by their terms, the terms alone are sufficient for making relational propositions true, so we can do with no R-internal relations at all (see Armstrong 1978, p. 86; Campbell 1990, p. 38; and more recent Simons 2016; Lowe 2016). Interestingly enough, there is no comparable discussion concerning the second meaning of internal relation, which nevertheless prima facie do not seem to be so easy reducible (see, however, Yates 2016). It is so, presumably, because M-internal relations are still usually considered to be R-internal at the same time.

I do not think that the supposed reducibility of R-internal relation has much effect on the discussion about the relational collapse. In worst case, if grounded relations really reduce to the properties, internalisation would mean not the change of the status of the relation from external to internal, but rather the transformation of external relation into a property of a thing, which would alone make true an appropriate relational judgment. For the sake of simplicity, however, I assume here non-reducibility of R-internal relations.

\section{Reversibility of Relational Collapse}

Uemov believed the transition of external systems into internal ones to be irreversible. That is why he called this phenomenon a relational collapse and claimed that it might help in determining the direction of time flow. Things that have internalised relations cannot get rid of them, they can only cease to exist. While external relations may internalise, internal relations cannot externalise. Unfortunately, the crucial thesis of the irreversibility of relational collapse was not much discussed by Uemov, who formulated only one brief and rather unclear argument for it (Uemov 1975, p. 100; 1978, p. 229). As far I know, there were also no considerations on this subject among his students, except for the apparently accidental sentence in one of the articles by Ludmila Terent'eva: "the reverse transition is precluded on the basis of the following 
arguments", after which nevertheless no arguments followed! (Terent'eva 2007, p. 14). I will now try to show that the distinction between the two senses of internal relations fundamentally undermines Uemov's argumentation.

Uemov attempted to prove that external systems, which have become internal under the influence of relation, can no longer return to their former state. In other words, "substrates of internal systems [...] exist in the conditions of the relational collapse" (Uemov 1975, p. 100; 1978, p. 229). According to Uemov, change of the relation in an internal system is impossible because its terms cannot change:

If the substrate [of an internal system] has not existed in the conditions of a relational collapse then this would mean that the elements of the substrate can mutually affect one another in a manner which negates that which has been fixed by the systems formative relation $R$ (Uemov 1975, p. 100; 1978, p. 229).

Uemov tried to justify this thesis with the following reasoning:

The transition from relation $R$ to relation $\neg R[\ldots]$ can be realized only by the functioning of external or internal factors. However, the external factors cannot by themselves change relation $R$ insofar as it remains internal for its correlates. External factors can affect relation $R$ only through the transition of the correlates of this relation. If the change of correlates of the internal relation can make that the relation ceases being internal then a way will have been found of changing the relation without changing the correlates themselves. This, however, is adverse to the very notion of the internal relation itself (Uemov 1975, p. 100; 1978, p. 229; italics mine-P. R.).

As a result, Uemov concluded, "if the external system changes into an internal system, then this system remains an internal system" (Uemov 1975, p. 100; 1978, p. 229-230).

It must be admitted, that this is rather unclear reasoning, and less elaborate than one could expect. Two theses, included in the italicized part of quotation, seem to be crucial for the argument:

(1) A change of internal relation must be a result of a change of its terms;

(2) A change of the terms of internal relation cannot affect the internality of the relation.

Uemov seems to suggest that these theses are connected in such a way that the negation (2) implies negation (1). Acknowledging the possibility that the terms can free themselves from an internal relation would therefore contradict the very nature of the internal relation. Therefore, the relational collapse is supposedly irreversible.

I am not going to analyse the structure of this argument in details. I just want to notice that if (1) is understood as $\neg \checkmark(\mathrm{p} \rightarrow \mathrm{q})$, and (2) as $\neg \vee(\mathrm{q} \rightarrow \mathrm{p})$, then though (2) $\rightarrow$ (1), it is not the case that $\neg(2) \rightarrow \neg(1)$. Most importantly, however, is that (1) and (2) 
involve different senses of the concept of internal relation. Formula (1) clearly applies to R-internal relations, that is, to relations grounded in the natures of terms. In this case, a relation can change only due to a change in the nature of these terms. Uemov pointed this out on numerous occasions. He wrote: "change of a [internal] relation is determined only by a change in correlated objects" (Uemov 1978, p. 238), or: "things can change a [internal] relation $R$ between them only through their own change" (Uemov 1978, p. 227). And what is the meaning of internal relation in (2)? It seems that it is not about Rinternal relations, but rather about the $\mathrm{M}$-internal ones, that is, about relations essential for the terms. For there are no obstacles for things to cease to be connected by a Rinternal relation. It could happen, for instance, that the Earth enlarged, and the Sun diminished, and as a result the Earth would become bigger than the Sun. Principle (2) is true therefore only for essential relations. It is not possible, for instance, that the number four cease to be greater than three, because their relation is constitutive of their identity. I conclude, that since principles (1) and (2) use internal relations in different senses, Uemov's argument is based on equivocation. Uemov wanted to show that things in Rinternal relations are also in M-internal relations. However, there is no such transition.

\section{Towards a General Theory of Internalisation and Externalisation}

It turns out, therefore, that Uemov's theory of relational collapse must be substantially revised. First of all, as I pointed out in Section 4, it is necessary to distinguish two meanings of the concept of internal relation and, consequently, two senses of internalisation of relations. Secondly, as I suggested in Section 5, the irreversibility of the internalisation is doubtful, certainly in the Russellian sense, and probably also in the Moorean one. However, Uemov's mistakes should lead not to the rejection of his intuitions, but rather to their development into a richer and broader general theory of internalisation and externalisation of relations.

I would like to introduce here the most important concepts of such a theory. First of all, the two senses of the concept of internalisation of a relation should be distinguished. The first kind, yielding R-internal relations, I suggest calling groundation, the second one, bringing M-internal relations, might be called essentialisation. Secondly, as the discussion on the reversibility of relational collapse reveals, there is also a possibility of externalisation of a relations. This process has also two variations, resulting from two senses of an external relation. The first type of externalisation can be called ungroundation, the second-accidentalisation of a relation (see Table 2).

Table 2 Key concepts of the general theory of internalisation and externalisation of relations

\begin{tabular}{lll}
\hline & Russell's sense & Moore's sense \\
\hline Internalisation & Groundation & Essentialisation \\
Externalisation & Ungroundation & Accidentalisation \\
\hline
\end{tabular}


Now I will briefly characterise each of these processes. Perhaps the most plausible sense of the concept of internalisation of relation is groundation. This occurs when at least one term of an ungrounded relation changes under its influence in the way that the relation becomes grounded in it. In other words, the groundation is simply the development of a habit. A person appointed to a new position may become accustomed to it, and her activity may begin to somehow result from her own nature. Similarly, a flexible material can take on a new shape under pressure, which after some time might become its own default shape. As Cicero used to say, consuetudo quasi altera natura. Habit becomes indeed a "second nature", at least in the sense that an object gains some new properties which ontologically ground its new dispositions.

The opposite is a process of ungroundation. If an object can become accustomed to something, then, in principle, it can also become unaccustomed. That is, the terms of relation may lose the properties which ground that relation. The relation may still continue to obtain, but now as a relation ungrounded in the natures of both terms. This also seems to be quite plausible. For instance, someone may for some reason lose inner disposition to do certain deeds and to play the role of the leader only from external impulses. The same is perhaps possible in the case of the rubber ball, which could, in appropriate physical circumstances, recover its flexibility. The second nature, namely the habit, although it may have a tendency to last, is not invariable and indelible.

Now, the concept of the essentialisation of relations is much more controversial from the ontological and logical points of view. Essentialisation means that a relation become essential for its terms. This is not merely a habit, but rather ontological addiction. Something that was previously unnecessary for an object becomes, after some time, necessary for its existence. In this case, addiction would be indeed second nature, but now in the sense of being essential for the object. The first problem, however, is that essences are usually understood as unchangeable. Essential properties are supposed to be necessary, that is, they should characterise the object in all possible worlds in which it exists, and so the object must also have them throughout its entire existence in one world. It should be likewise with essential relations. They should be unchangeable, that is, they should relate their terms in all possible worlds in which they exist and throughout their existence. The supposed immutability of essences excludes the possibility that objects could acquire new essential properties or enter in new essential relations. The concept of the essentialisation of properties or relations therefore requires a deep modification of the notion of metaphysical necessity. If one accepts that something can become essential for the object, the notion of necessity must be relativised to time. Together with Błażej Skrzypulec, we tried to show how such a relativisation of modality can be done (Skrzypulec and Rojek 2018). Relative necessity can be defined as truth in all possible histories of an object over a period of time. In particular, the concept of prospective necessity may be introduced as follows: property $F$ is prospectively necessary for an object $a$ if and only if $a$ has $F$ at every later point of its all possible histories (Skrzypulec and Rojek 2018, p. 11-12). In a similar way, one can define the prospective necessity of a relation. Only on the basis of so modified concept of necessity can it be said that some property or relation really becomes essential for an object at some point. The classic concept of absolute necessity, as it seems, exclude such possibility.

The other problem with changeable essences concerns the identity of changing objects. It is usually hold that essences provide fundamental criteria for identity in 
time; the same thing may change its accidents, but the lost of the essence means the ultimate ceasing of the object. Perhaps, then, in case of new essences we should speak about new objects. This worry reminds a similar doubt concerning the possibility of relation changing their status form externality to internality (and vice versa). As I indicated above in Section 2, the very idea of relational collapse presuppose that we really see one changing relation, not many subsequent different cases. The same is true in this case. If we allow the concept of changing essences, we should consequently give up essences as criteria of identity in time. What, then, would provide us such criteria, remains rather unclear, but this cannot be discussed here further.

Now, if we notwithstanding accept the possibility of becoming addicted to relations, it seems that we should also allow for becoming independent of them. The reverse process to the essentialisation of relations can be called the accidentalisation of relations. In accidentalisation some essential relations become accidental for their terms. Something that was necessary for the existence of an object becomes unnecessary at some point. For example, for many organisms, a relation with the mother is necessary in the early stages of life, but it ceases to be so over some time. In a similar way, one can become independent from using alcohol or drugs. An ontological account of the accidentalisation of relations is just as problematic as an account of essentialisation. This concept is possible only if one gives up the idea of absolute necessity and relativises it to time. Just as one can define a prospective necessity, one can also define retrospective necessity: property $F$ is retrospectively necessary for an object $a$ if and only if $a$ has $F$ at every earlier point of all its possible histories (Skrzypulec and Rojek 2018, p. 13-14). Similarly, one can define the retrospective necessity of having a relation.

Once one has decided to relativise the notion of necessity, the concept of accidentalisation turns out to be just as acceptable as the concept of essentialisation. From a logical point of view, there is no asymmetry between them. Moreover, nothing prevents us from defining an even weaker concept of relative necessity, namely having a certain property or relation in all possible histories during some determined period of time (Skrzypulec and Rojek 2018, p. 14-16). It turns out, then, that the concept of relational collapse, if it is possible at all, must be relative and reversible.

\section{Conclusion}

Over 40 years ago, Avenir Uemov formulated the inspiring idea of relational collapse. Unfortunately, his idea has not influenced the mainstream ontological discussions. In this text, I tried to revive his concept and placed it in the context of contemporary discussions in analytic philosophy. As I showed, the idea of relational collapse is based on an ambiguous concept of internal relation. Therefore, one should speak not so much about the internalisation of relations, but rather about two different processes, namely groundation and essentialisation. Moreover, contrary to Uemov, both of these processes seem in principle to be reversible. Therefore, one should speak not only about groundation and essentialisation, but also about the ungroundation and accidentalisation of relations. As I pointed out, the concepts of essentialisation and accidentalisation require a serious modification of the concept of necessity, which in the 
classic version does not allow any change. In this way, the original concept of Uemov was developed here towards a general theory of internalisation and externalisation of relations.

Now I would like to return to the supposed example of relational collapse in sociology described by Arnold Tsofnas. I think that the general account developed here allows a more accurate view of social internalisation of norms. It seems that this process has two distinct aspects. The first one is groundation. People accept social norms and form appropriate attitudes in the process of socialisation, thanks to which their obedience results not so much from the threat of external sanctions but rather from their internal dispositions. As a result, social norms are really grounded in human natures. They become, as Tsofnas wrote, "habit" and "inner need". This means that normative laws actually become internal relations, but only in the Russellian sense. However, there can also be a deeper internalisation of norms, i.e. embracing not only their groundation but also their essentialisation. In this case, people would not only have appropriate dispositions, but would also be unable to act differently. As Tsofnas wrote in the passage quoted above, in such case "you simply cannot sit at the table with dirty hands". In such a situation, one could speak not only of getting used to, but also of becoming addicted to a certain way of action. Normative laws in such a case would turn out to be internal relations not only in the Russelian, but also in the Moorean sense. Of course, neither groundation nor essentialisation are absolute here. In principle, each of these processes is reversible, although probably at a different cost. Naturally, the ontology of norms internalisation still raises serious questions. It seems to me, however, that thanks to the concepts introduced here, it is possible to develop its sound ontological interpretation (for details, see Rojek and Skrzypulec forthcoming).

It turns out, then, that, years later, the forgotten concept of Uemov may quite unexpectedly become a source of inspiring intuitions. Thanks to this, the discussion on internal and external relations that has been going on in analytic philosophy for more than a century can be supplemented with a dynamic perspective. The theory completed in this way may find many applications. Although it is probably unable to be a desired criterion for the time flow in physics, it can provide powerful tools to analyse the concept of internalisation of norms in sociology.

Acknowledgments This publication was generously supported by a grant from the Polish National Science Center, no. 2013/11/D/HS1/04332. The first version of this paper was presented on December 10, 2015, at a meeting of the Prof. Arnold Tsofnas International Logical and Methodological Seminar in Odessa, Ukraine, and then on December 14, 2015, at a meeting of the Ontology Department of the Institute of Philosophy of the Jagiellonian University in Krakow, Poland. I am grateful for helpful comments to Karol Kleczka, Sebastian Kołodziejczyk, Karol Lenart, Leonid Leonenko, Dmitrii Liashenko, Filip Płaneta, Stanisław Ruczaj, Nikolai Savusin, Błażej Skrzypulec, Liudmila Sumarokova, Gennadii Shtakser, Liudmila Terent'eva, Jakub Węgrecki, and an anonymous referee of this journal.

Open Access This article is licensed under a Creative Commons Attribution 4.0 International License, which permits use, sharing, adaptation, distribution and reproduction in any medium or format, as long as you give appropriate credit to the original author(s) and the source, provide a link to the Creative Commons licence, and indicate if changes were made. The images or other third party material in this article are included in the article's Creative Commons licence, unless indicated otherwise in a credit line to the material. If material is not included in the article's Creative Commons licence and your intended use is not permitted by statutory regulation or exceeds the permitted use, you will need to obtain permission directly from the copyright holder. To view a copy of this licence, visit http://creativecommons.org/licenses/by/4.0/. 


\section{References}

Armstrong, D. M. (1978). Universals and scientific realism (Vol. 2). Cambridge: Cambridge University Press. Bertalanffy, L. (1968). General system theory: Foundations, development, applications. New York: George Braziller.

Bogdanov, A. A. (1906). Empiriomonizm. Stat'i po filosofii. Saint Petersburg: Izdatel'stvo S. Dorovatovskogo i A. Charushnikova.

Campbell, K. (1990). Abstract Particulars. Cambridge: Blackwell.

Candlish, S. (2007). The Russell/Bradley dispute and its significance for twentieth-century philosophy. New York: Palgrave Macmillan.

Ershova-Babenko, I. V. (1992). Metodologiia issledovaniia psikhiki kak sinergeticheskogo ob'ekta. Odessa: Odekom.

Ewing, A. C. (1934). Idealism: A critical survey. London: Methuen.

Fine, K. (2015). Unified foundations for essence and ground. Journal of the American Philosophical Association, 1(2), 296-311.

García Encinas, M. J. (2013). On necessary but external relations. Review of Contemporary Philosophy, 12, 93-101.

Hakkarainen, J., Keinänen, M., \& Keskinen, A. (2018). Taxonomy of relations: Internal and external. In D. Bertini \& D. Migliorini (Eds.), Relations. Ontology and philosophy of religion (pp. 93-107). Verona: Mimesis International.

Heil, J. (2016). Causal relations. In A. Marmodoro \& D. Yates (Eds.), The metaphysics of relations (pp. 127137). Oxford: Oxford University Press.

Heisenberg, W. (1974). The notion of a "closed theory" in modern science. In W. Heisenberg (Ed.), Across the frontiers (pp. 39-46). New York: Harper \& Row.

Holton, G. (1993). Science and anti-science. Cambridge: Harvard University Press.

Johansson, I. (1989). Ontological investigations. London: Routledge.

Kessidis, T. (2002). Modern aspects of Aristotle's teachings on time. Filosofia Tomos, 32, 174-184.

Leonenko, L. (2000/2001). The language of ternary description and its founder. Modern Logic, 8(3-4), 31-52.

Lowe, E. J. (2016). There are (probably) no relations. In A. Marmodoro \& D. Yates (Eds.), The metaphysics of relations (pp. 100-112). Oxford: Oxford University Press.

Marmodoro, A., \& Yates, D. (2016). Introduction: The metaphysics of relations. In A. Marmodoro \& D. Yates (Eds.), The metaphysics of relations (pp. 1-18). Oxford: Oxford University Press.

Maurin, A.-S. (2002). If tropes. Dordrecht: Kluwer Academic Publishers.

Meinertsen, B. R. (2011). Distinguishing internal, external and grounded relations. Grazer Philosophische Studien, 83(1), 113-122.

Moore, G. E. (1922). External and internal relations. In Philosophical studies (pp. 276-309). New York: Harcourt, Brace and Co..

Popper, K. R. (1945). The open society and its enemies. In The Spell of Plato (Vol. 1). London: Routledge.

Rojek, P. (2018). Regresy podobieństwa. Podwójny relacyjny argument przeciwko nominalizmowi tropowemu. Filozofia Nauki, 2(26), 13-40.

Rojek, P. \& Skrzypulec B. (forthcoming). Ontology of social internalisation.

Russell, B. (1910). The monistic theory of truth. In Philosophical essays (pp. 150-169). London: Longmans, Green and Co.

Savusin, N. P. (2016). Vzaimosviaz' kategorii veshch', svoistvo i otnoshenie v terminakh iazyka IATO. In L. L. Leonenko, D. N. Liashenko, K. V. Raikhert, \& L. N. Terent'eva (Eds.), Uemovskie chteniia I-IV (2013-2016). Materialy Nauchnykh chtenii pamiati Avenira Uemova (pp. 257-265). Pechatnyi dom: Odessa.

Shoemaker, S. (1980). Causality and properties. In P. van Inwagen (Ed.), Time and cause (pp. 109-135). Dordrecht: Reidel.

Shtakser, G., \& Leonenko, L. (2011). Tracks of relations and equivalences-based reasoning. Studia Logica, 97 , 385-413.

Simons, P. (2016). External relations, causal coincidence, and contingency. In A. Marmodoro \& D. Yates (Eds.), The metaphysics of relations (pp. 113-126). Oxford: Oxford University Press.

Skrzypulec, B., \& Rojek, P. (2018). Dynamic essences: absolute, prospective, retrospective, and relative modalities. Studia Humana, 7(1), 3-20.

Swoyer, C. (1982). The nature of natural laws. Australasian Journal of Philosophy, 60(3), 203-223.

Terent'eva, L. N. (2007). Nauka i antinauka v sistemno-parametricheskom izmerenii. Visnik Odes'kogo natsional'nogo universitetu. Filosofiia, 15, 7-18. 